\title{
EFFICACY OF MEDICINAL PLANTS AGAINST HUMAN PATHOGENS ISOLATED FROM WESTERN HIMALAYAS OF HIMACHAL PRADESH
}

\author{
NEHA CHAUHAN, UMAR FAROOQ, MOHAMMAD AZHAR KHAN*
}

Molecular and Immuno-Parasitology Research Laboratory, Faculty of Applied Sciences and Biotechnology, Shoolini University, Solan, Himachal Pradesh, India. Email: mk.azhar1@gmail.com

Received: 08 May 2017, Revised and Accepted: 09 June 2017

\section{ABSTRACT}

Objective: The present study was aimed to evaluate the antibacterial effect of Himalayan medicinal plants on several human pathogens.

Methods: The leaves of Mesua ferrea, Cannabis sativa, and Urtica dioica, bark of Juglans regia, Glycyrrhiza glabra, fruit of Terminalia chebula, and seed of Piper nigrum were dried and powdered before methanolic extraction (ME). Antibacterial assay of MEs was performed against Bacillus subtilis, Staphylococcus aureus, Escherichia coli, Pseudomonas aeruginosa, and Klebsiella pneumoniae using agar well diffusion method. The minimum inhibitory concentrations of these extracts were assessed using microdilution method. The phytochemical analysis of these extracts was carried out to know the bioactive compounds and was fractionated with various solvents such as chloroform, butanol, ethyl acetate, and hexane to isolate the bioactive compound.

Results: The ME of $C$. sativa was found highly active, followed by T. chebula, J. regia, G. glabra, and M. ferrea against these pathogens. While the extracts of $U$. dioica and P. nigrum found less effective. MIC values of $J$. regia extract were found much more significant $(0.219 \mathrm{~g} / \mathrm{ml})$. The antibacterial assay of fractions revealed that the chloroform fraction was highly active against all the pathogens than those of ethyl acetate, butanol, and hexane.

Conclusion: It was concluded from the present study that methanol was a good solvent for isolating compounds from medicinal plants and also favors the traditional uses of medicinal plants as antibacterial agents and as a potential source for the new drug discovery. It could also be possible that the compound responsible for antibacterial activity must be present in chloroform fraction of J. regia.

Keywords: Antibacterial activity, Medicinal plants, Methanolic extracts, Human pathogens, Phytochemicals, Fractionation.

(C) 2017 The Authors. Published by Innovare Academic Sciences Pvt Ltd. This is an open access article under the CC BY license (http://creativecommons. org/licenses/by/4. 0/) DOI: http://dx.doi.org/10.22159/ajpcr.2017.v10i9.19708

\section{INTRODUCTION}

Plants have been used for centuries as a remedy for human diseases as they contain components of therapeutic values. They are natural sources of antimicrobial agents primarily due to large biodiversity and relatively large quantity of metabolites that can be extracted from them [1,2]. The traditional values of these plants in medicines led researchers to make them an alternative form of health care to investigate the antimicrobial therapy $[3,4]$. The natural products of plants, animals, and minerals have been the basis of treatment of diseases from time immemorial. The history of medicine includes many ludicrous therapies; ancient wisdom has been the basis of modern medicine and will remain as one of the important sources of future medicine and therapeutics. The $80 \%$ of world's population are relied on medicinal plants. In India, the medicinal plants as therapeutics remain the most important component of the traditional medicinal system $[5,6]$. A lot of work has been reported on medicinal plants as constituents of antimicrobial and phytochemicals. The treatment of microbial infections is considered as possible alternatives over chemically synthesized drugs to whom resistant have been developed by several infectious microorganisms $[7,8]$. The antimicrobial activity of plant extracts is due to their various phytoconstituents.

These compounds usually include the secondary metabolites, which function as phytoprotectants and respond to environmental changes in plants. However, in humans, the compounds have more beneficial effects $[9,10]$. On the basis of literature found on the beneficial aspects of medicinal plants, the present study is aimed to evaluate the antimicrobial effect of some medicinal plants used in Ayurveda and traditional medicinal system for the treatment of manifestations caused by microorganisms. Therefore, methanolic extracts (MEs) of the following 7 medicinal plants from different families were tested for their potential activity against microbial pathogens (Escherichia coli, Klebsiella pneumoniae, Staphylococcus aureus, Pseudomonas aeruginosa, and Bacillus subtilis).

\section{METHODS}

Sample collection

The bacterial strains E. coli (MTCC-739), K. pneumoniae (MTCC-39), S. aureus (MTCC-737), P. aeruginosa (MTCC-741), and B. subtilis (MTCC-441) were collected from IMTECH, Chandigarh. The microorganisms are subcultured in nutrient broth and incubated at $37^{\circ} \mathrm{C}$ for $24 \mathrm{hrs}$ before the experiment. A total of 7 authenticated medicinal plants, i.e., Juglans regia, Mesua ferrea, Glycyrrhiza glabra, Urtica dioica, Pepper nigrum, and Terminalia chebula were collected from different areas of Himachal Pradesh. The fresh leaves of J. regia, M. ferrea, Cannabis sativa, U. dioica, and the fresh seeds, fruits, and roots of P. nigrum, T. chebula, and G. glabra, respectively, were collected in the month of March from Solan district of Himachal Pradesh located at the altitude of $800 \mathrm{~m}$.

\section{Preparation and extraction of the plant material}

The plant parts were collected and surface sterilized with distilled water and then with mercury chloride $\left(\mathrm{HgCl}_{2}\right)$. The parts were dried at room temperature and grounded into powder using pestle and mortar. The powders were weighed and stored. The dried powdered of the plant was extracted with methanol by extraction process using orbital shaker for 3d (72 hrs). The crude extract was concentrated and dried using rotary vacuum evaporator.

Evaluation of antimicrobial activity of plant extract Antimicrobial activity of various plant extracts was assessed by welldiffusion method [11]. The turbidity of the subcultured microorganisms 
was adjusted with sterile distilled water using 0.5 McFarland as standard $(\sim 1.5 \times 108$ cells $/ \mathrm{ml})$. Mueller Hinton Agar (HiMedia) was prepared by dissolving readymade agar powder in distilled water. Agar plates were prepared and inoculated with the test microorganisms by spread plate method. The plates were left undisturbed for $30 \mathrm{~min}$ at room temperature. The dried MEs were weighed and dissolved in dimethyl sulfoxide (DMSO) and used in triplicates. Then, the prepared extracts were added in the wells in a constant concentration of $50 \mu \mathrm{l} /$ well. The standard was also prepared for the antibiotic as a positive control ciprofloxacin (HiMedia). DMSO was also added in a well as negative control to make sure that the solvent used for dissolving the extracts do not have antimicrobial activity. Then, the plates were incubated at $37^{\circ} \mathrm{C}$ for $24 \mathrm{hrs}$ in an upright position. After incubation, the zone of inhibition was measured and compared with the standard antibiotic zone.

\section{Minimum inhibitory concentration (MIC)}

The MIC assay was performed for those plants whose extract was found active by well diffusion susceptibility assay (inhibition zone $>10 \mathrm{~mm}$ ) $[12,13]$. The MIC values were determined by microdilution method using 96 well plates. The 96-well plates were prepared by dispensing $100 \mu \mathrm{l}$ of nutrient broth into each well. $100 \mu \mathrm{l}$ was taken from the stock solution of tested extracts (concentration of $5 \mathrm{mg} / \mathrm{ml}$ ) and added into the first well of the plate. Then, two-fold serial dilutions were performed using a micropipette. The obtained concentration range was from $5 \mathrm{mg} / \mathrm{ml}$, and then added $50 \mu \mathrm{l}$ of inoculum to each well except negative control. The positive control of antibiotic (ciprofloxacin), negative control (nutrient broth), broth alone, and the inoculum alone were also put in the experiment. The test plates were incubated at $37^{\circ} \mathrm{C}$ for $24 \mathrm{hrs}$. The lowest sample concentration showing clear well and inhibited complete growth was taken as MIC value [14].

\section{Phytochemical screening}

Phytochemical analysis of methanol leaf extracts of J. regia, U. dioica, M. ferrea, and C. sativa was carried out qualitatively to test for the presence of carbohydrates, proteins, tannins, phenols, flavonoids, cardiac glycosides, phytosterol, saponins, and alkaloids [15].

\section{Fractionation of the plant extracts}

Fractionation was done to separate the active components of the plants. MEs were taken in a beaker and diluted with $5 \% \mathrm{HCl}$. After complete dissolution, separated liquid layer and repeated till solution appeared colorless. Filtered $\mathrm{HCl}$ treated layer and treated with $10 \mathrm{ml}$ chloroform. Two layer was formed, i.e., chloroform layer and aqueous layer, the chloroform layer was separated in a beaker and filtered through a funnel containing Whatman filter paper and anhydrous sodium sulfate to hold the $\mathrm{H}_{2} \mathrm{O}$ molecules and repeated 2-3 times and evaporated. Basified aqueous solution with ammonia solution and again treated with chloroform, ethyl acetate, n-butanol, and hexane, respectively. The layers were separated and evaporated in the same manner as chloroform. The different fractions were then collected in separate vials and analyzed for antimicrobial sensitivity assay using agar well diffusion method.

\section{Antibacterial susceptibility assay of fractions}

Antimicrobial activities of the fractions were performed using agar well diffusion method. The fractions (i.e., butanol, chloroform, ethyl acetate, and basified chloroform) were dissolved in $1000 \mu \mathrm{l}$ of the DMSO in an Eppendorf and mixed well. Same protocol was followed for the antimicrobial assay and MIC of fractions as described earlier for the susceptibility assay of plant extracts. The data were analyzed by mean and standard (mean \pm standard deviation) deviation using GraphPad prism.

\section{RESULTS}

\section{Bacterial isolates}

A total of five laboratories adopted bacterial isolates two Gram-positive (B. subtilis and S. aureus) and three Gram-negative (E. coli, Klebsiella pneumonia, and P. aeruginosa) as shown in Fig. 1 were used for the study, which were obtained from IMTECH and characterized at molecular and Immuno-Parasitology Research Laboratory, and cultured on nutrient agar plates.

\section{Antimicrobial activity of ME}

Leaf, root, fruit, and bark were selected as experimental materials to screen their potential antimicrobial activity. MEs were investigated for the antimicrobial activity (Table 1) against the bacterial species mentioned. The antibacterial activity of different plant extracts against the pathogenic bacteria showed varied levels of inhibition. As shown in Table 1, the present study revealed that out of seven medicinal plants only 5 showed potential antibacterial activity

Table 1: Antibacterial effect of the ME against several bacterial strains

\begin{tabular}{|c|c|c|c|c|c|c|c|}
\hline Bacterial strains & S. aureus & E. coli & P. aeruginosa & K. pneumoniae & B. subtilis & $-\mathrm{C}$ & $+\mathrm{C}$ \\
\hline Plants ME & \multicolumn{7}{|c|}{ Zones of inhibition in mm } \\
\hline J. regia & $11.6 \pm 1.1$ & $12.3 \pm 0.5$ & $14.3 \pm 1.5$ & $10.6 \pm 1.1$ & $11.6 \pm 1.5$ & - & $23 \pm 0$ \\
\hline M. ferrea & $11.0 \pm 0.0$ & - & $10.5 \pm 0.7$ & $11.3 \pm 1.5$ & $11.0 \pm 1.0$ & - & $24 \pm 0$ \\
\hline G. glabra & $13.6 \pm 1.5$ & $12 \pm 2.0$ & $11.6 \pm 2.1$ & $13.0 \pm 3.0$ & $11.0 \pm 1.0$ & - & $22 \pm 0$ \\
\hline T. chebula & $16.0 \pm 1.7$ & $15.6 \pm 1.1$ & $15.6 \pm 1.1$ & $22.3 \pm 1.5$ & $24.0 \pm 0.0$ & - & $18 \pm 0$ \\
\hline C. sativa & $21.6 \pm 0.5$ & $21.6 \pm 0.5$ & $24.0 \pm 1.0$ & $18.0 \pm 1.0$ & $23.6 \pm 0.5$ & - & $24 \pm 0$ \\
\hline P. nigrum & - & - & - & - & - & - & $19 \pm 0$ \\
\hline
\end{tabular}

ME: Methanolic extract, mm: Millimeter, +C: Positive control, -C: Negative control, -: No zone of inhibition, E. coli: Escherichia coli, P. aeruginosa: Pseudomonas aeruginosa, K. pneumoniae: Klebsiella pneumoniae, B. subtilis: Bacillus subtilis, S. aureus: Staphylococcus aureus, C. sativa: Cannabis sativa, J. regia: Juglans regia, G. glabra: Glycyrrhiza glabra, M. ferrea: Mesua ferrea, U. dioica: Urtica dioica, P. nigrum: Piper nigrum

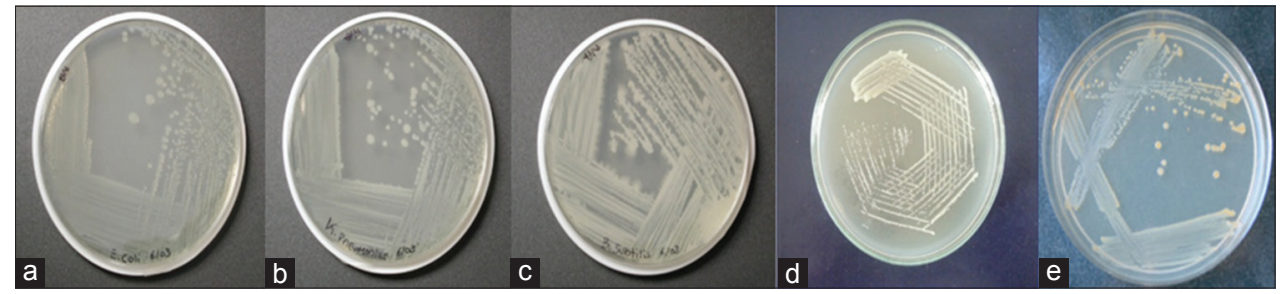

Fig. 1: Growth of microorganism on nutrient agar (a) Escherichia coli (b) Klebsiella pneumoniae (c) Bacillus subtilis (d) Pseudomonas aeruginosa and (e) Staphylococcus aureus 


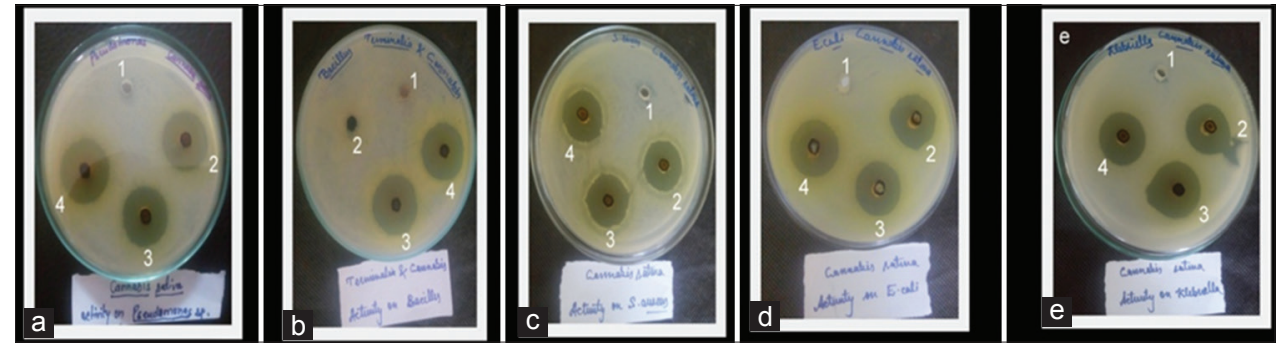

Fig. 2: Antibacterial activity of methanolic leaf extract of Cannabis sativa against the test bacteria (a) Pseudomonas aeruginosa (b) Bacillus subtilis (c) Staphylococcus aureus, and (d) Escherichia coli (e) Klebsiella pneumoniae

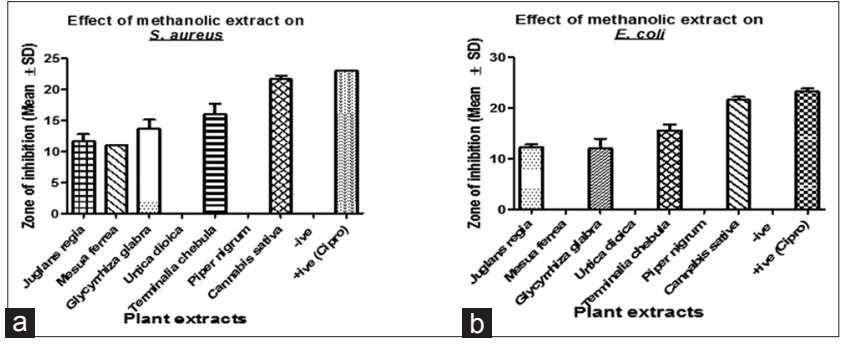

Fig. 3: ( $a$ and $b$ ) Graphical representation of plant extracts showing varied degree of sensitivity against $S$. aureus and Escherichia coli

against S. aureus, P. aeruginosa, K. pneumoniae, B. subtilis, and E. coli. Although, $U$. dioica and P. nigrum do not show any activity against any pathogen.

The results obtained by measurement of zone of inhibition were presented in Table 1 and Figs. 2-4, the MEs of C. sativa showed a maximum zone of inhibition against $P$. aeroginosa, followed by B. subtilis, E. coli, S. aureus, and K. pneumoniae, respectively.

The MEs of T. chebula showed the highest antimicrobial effect on B. subtilis followed by K. pneumoniae, S. aureus, and E. coli. Whereas the J. regia, M. ferrea, and G. glabra have showed near about similar effect against E. coli, P. aeruginosa, B. subtilis, and K. pneumoniae, respectively (Table 1, Figs. 2-4).

\section{Determination of MIC}

Broth dilution method was used to determine the MIC values of MEs of M. ferrea, J. regia, G. glabra, and C. sativa. Microdilution method was used to determine the lowest plant extracts concentration that was inhibiting the growth of the bacteria and found effective in the evaluation of best activity of medicinal plants.

MIC values of MEs of Mesua ferrea, J. regia, and G. glabra revealed that the MIC of $J$. regia was much more significant as compare to the other plants, i.e., 0.219 as shown in Table 2 .

\section{Phytochemical screening}

MEs which had shown good antibacterial activities (i.e., J. regia, G. glabra, M. ferrea, and C. sativa) were screened for the presence of phytochemical compounds. Investigation of the phytochemical screening summarized in Table 3. Phytochemical screening on the crude methanol extracts of four medicinal plants was performed in the test tube. The observations (Table 3) revealed the presence of secondary metabolites such as saponins, tannins, alkaloids, phytosterol, flavonoids, terpenoid, glycosides, phlobatannins, triterpenoids, and cardiac glycosides. The commonly identified components of importance in the four plant extracts include flavonoids, cardiac, glycosides, and saponins.

In addition, tannins were present in J. regia and C. sativa, phlobatannins were present in J. regia, M. ferrea, and C. sativa, and carbohydrates and saponins were present in all the four plant extracts. Alkaloids
Table 2: MIC (MIC in $\mathrm{mg} / \mathrm{ml}$ ) of J. regia, G. glabra, M. ferrea, and C. sativa ME against bacterial strains

\begin{tabular}{lllll}
\hline $\begin{array}{l}\text { Extracts/ } \\
\text { bacterial strains }\end{array}$ & C. sativa & J. regia & G. glabra & M.ferrea \\
\hline E. coli & 0.438 & 0.438 & 0.875 & 1.750 \\
P. aeruginosa & 0.219 & 0.219 & 0.875 & 1.750 \\
K. pneumoniae & 0.875 & 0.219 & 0.875 & 2.500 \\
B. subtilis & 0.438 & 0.219 & 0.438 & 0.875 \\
S. aureus & 0.219 & 0.438 & 0.875 & 0.875 \\
\hline
\end{tabular}

E. coli: Escherichia coli, P. aeruginosa: Pseudomonas aeruginosa,

K. pneumoniae: Klebsiella pneumonia, B. subtilis: Bacillus subtilis, S. aureus:

Staphylococcus aureus, C. sativa: Cannabis sativa, J. regia: Juglans regia,

G. glabra: Glycyrrhiza glabra, M. ferrea: Mesua ferrea, MIC: Minimum inhibitory concentrations

Table 3: Phytochemical constituents of ME of J. regia, G. glabra, M. ferrea, and C. sativa

\begin{tabular}{lllll}
\hline $\begin{array}{l}\text { Phytochemical } \\
\text { constituents }\end{array}$ & ME & & & \\
\cline { 2 - 5 } & J. regia & M.ferrea & G. glabra & C. sativa \\
\hline Phenols & + & + & + & + \\
Flavonoids & + & + & + & + \\
Tannins & + & + & + & + \\
Alkaloids & + & + & + & + \\
Phlobatannins & + & + & - & - \\
Fixed oils and fats & - & - & - & - \\
Cardiac glycosides & + & + & + & + \\
Saponins & + & + & - & - \\
Amino acids & - & - & - & - \\
Carbohydrates & - & - & - & - \\
Terpenoids & + & + & + & + \\
Steroid & - & - & - & - \\
\hline
\end{tabular}

+: Represents presence of the phytoconstituent, -: Represents absence of the phytoconstituent. J. regia: Juglans regia, M. ferrea: Mesua ferrea, G. glabra: Glycyrrhiza glabra, C. sativa: Cannabis sativa

Table 4: Antimicrobial activity of fraction against $S$. aureus, E. coli, P. aeruginosa, Klebsiella sp., and Bacillus sp.

\begin{tabular}{llll}
\hline Bacterial strains & \multicolumn{2}{l}{ J. regia fractions } \\
\cline { 2 - 4 } & \multicolumn{2}{l}{ Zones of inhibition in mm } \\
\cline { 2 - 4 } & Butanol & Chloroform & Ethyl acetate \\
\hline E. coli & $8 \pm 0.001$ & $20 \pm 0.001$ & $9 \pm 0.002$ \\
B. subtilis & $10 \pm 0.002$ & $21 \pm 0.001$ & $7 \pm 0.001$ \\
P. aeruginosa & $10 \pm 0.002$ & $21 \pm 0.002$ & $10 \pm 0.001$ \\
K. pneumoniae & $10 \pm 0.001$ & $24 \pm 0.001$ & $10 \pm 0.002$ \\
S. aureus & $9 \pm 0.002$ & $19 \pm 0.001$ & $10 \pm 0.001$ \\
\hline
\end{tabular}

S. aureus: Staphylococcus aureus, E. coli: Escherichia coli, J. regia: Juglans regia P. aeruginosa: Pseudomonas aeruginosa, B. subtilis: Bacillus subtilis and K. pneumoniae: Klebsiella pneumoniae

were also found in all four plant extracts (Table 3). The antimicrobial (antibacterial and antifungal) activity of the plant extracts is due to the 


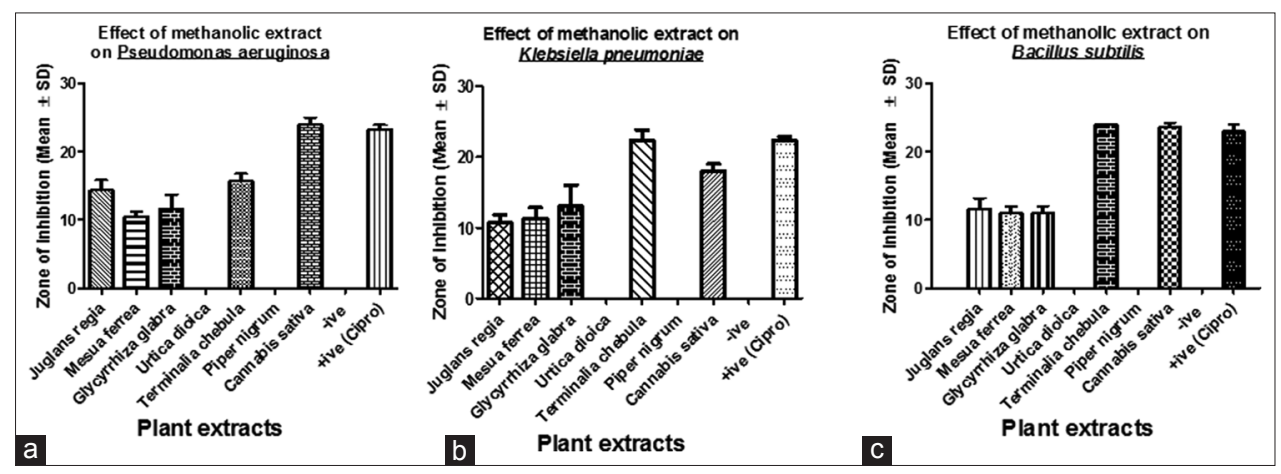

Fig. 4: (a-c) Graphical representation of plant extracts showing a varied degree of sensitivity against Pseudomonas aeruginosa, Klebsiella pneumoniae, and Bacillus subtilis

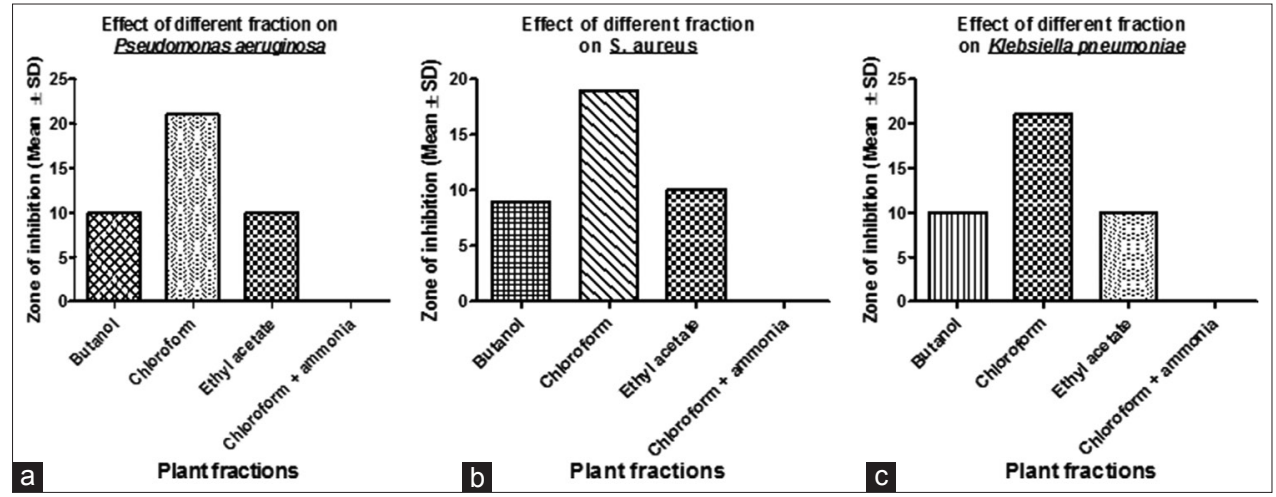

Fig. 5: (a-c) Graphical representation of methanolic extract fraction showing varied degree of sensitivity against Pseudomonas aeruginosa, Staphylococcus aureus, and Klebsiella pneumoniae

presence of these active compounds which may be acting independently or synergistically with other compounds.

\section{Fractionation of the most active plant extracts}

The antimicrobial activity of fractions

MEs of J. regia were fractioned using LLE method. Fraction of butanol, chloroform, basified chloroform, and ethyl acetate was tested against human pathogen. The antimicrobial activity of these plants was tested against these bacterial strains. The chloroform fraction showed the highest zone of inhibition against $K$. pneumoniae, followed P. aeruginosa and B. subtilis (Table 4 and Figs. 5 and 6).

The chloroform fraction was found highly active against E. coli $(20 \mathrm{~mm}$ zone) followed by $S$. aureus (19 mm; Table 4). The least active fractions were ethyl acetate and butanol. On the other hand, basified chloroform does not show any result against all of five bacteria.

\section{DISCUSSION}

Many naturally occurring compounds found in plants, herbs, and spices have been shown to possess antimicrobial functions and serve as a source of antimicrobial agents against pathogens $[16,17]$. Therefore, the development of new antimicrobial agents for the treatment of bacterial infections is of increasing interest. The main objective of the present study was to evaluate the ability of selected medicinal plants extract to inhibit the growth of pathogenic bacteria. In our study, agar well diffusion method was used to assess the activity of plants extracts, and significant zones of inhibitions were observed. The ME of $C$. sativa was found highly active followed by T. chebula, J. regia, G. glabra, and M. ferrea, respectively, against these pathogens. A fairly similar study was done by Naveed et al., on the leave extract of $C$. sativa [18] which exerted pronounced antibacterial activity against $S$. aureus, $P$. aeruginosa, and E. coli, whereas the extracts of $U$. dioica and P. nigrum did not show any significant inhibitory effects.

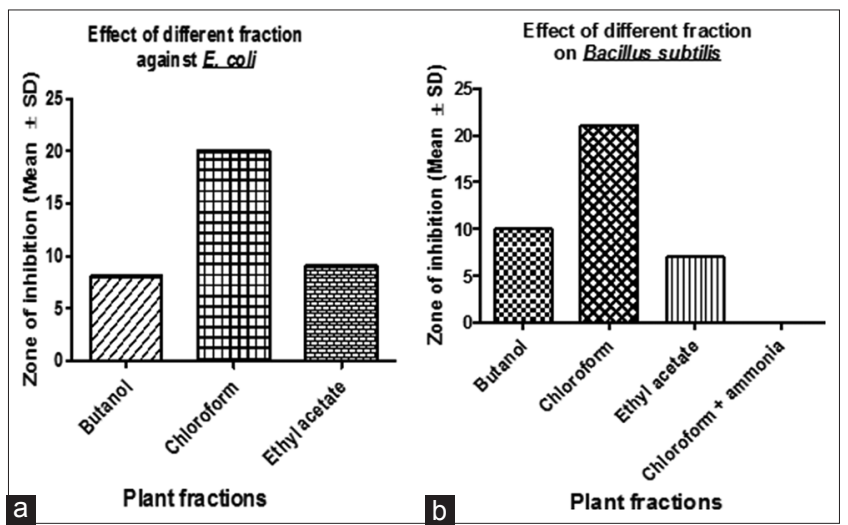

Fig. 6: ( $a$ and b) Graphical representation of various plant fractions showing varied degree of sensitivity against Escherichia coli and Bacillus subtilis

Microplate dilution method determines the MIC values of MEs of M. ferrea, J. regia, and G. glabra. The study revealed that the MIC values of J. regia were much more significant as compare to the other plants.J. regia bark is used in Iranian folk medicine as antimicrobial medicine [19,20]. This study also shows the presence of different phytochemicals with biological activity that can be of valuable therapeutic index. The result of phytochemicals showed that the plant contains more or less same components such as alkaloid, phlobatannins, saponins, terpenoids, steroids, glycosides, carbohydrates, flavonoids, and tannins. The alkaloids have been investigated for many pharmacological properties including antiprotozoal, cytotoxic, antidiabetic [21], and anti-inflammatory [22] properties, but there are only a few reports of antimicrobial properties. Baravalia et al. have shown the importance of polyphenols as antimicrobial compounds [23]. Polyphenols and 
flavonoids exhibit a wide range of biological effects and antibacterial activity [24-27]. Tannins have amazing stringent properties. They are known to hasten the healing of wounds and inflamed mucous membranes [28]. Tannins are also known for their antimicrobial activity $[29,30]$. Prasad et al. have reported the growth inhibition of many fungi, bacteria, and viruses by tannins [31]

ME was fractioned using LLE method. The chloroform fraction showed the highest zone of inhibition as compared to the other fractions. Asha et al. similarly reported that the chloroform and ethyl acetate fractions of J. regia were much more effective on these pathogenic strains [32]. A similar observation from the study done by Raj et al. reveals that chloroform extract fractions had highest antibacterial potential against all pathogenic microbes studied [33]. Hence, we can discuss from the above result that the compound responsible for the antibacterial activity must be present in chloroform that had potent antimicrobial activity.

\section{CONCLUSION}

It can be concluded that the fraction of medicinal plants showed potent antimicrobial activities against the tested bacterial strains. The antimicrobial activities may be due to strong occurrence of active compounds, i.e., saponins, tannins, alkaloids, steroids, phenols, and flavonoids. However, these medicinal plant species may be subjected to detailed phytochemicals and pharmacological studies to find out new drugs against pathogenic strains. Further studies are needed with these herbs to isolate, characterize, and elucidate the structure of the bioactive compounds of the herbs which are responsible for the antimicrobial activity and other therapeutic values.

\section{ACKNOWLEDGMENT}

The authors would like to thank Shoolini University for the support and facilities. The authors are highly grateful to the Department of Science and Technology (DST) for the funding under DST-INSPIRE fellowship (INSPIRE regd.140568)

\section{REFERENCES}

1. Copp BR. Antimycobacterial natural products. Nat Prod Rep 2003;20(6):535-57.

2. Yu R, Li X, Zhou X, Shi Q, Tang H. Expression, purification, and characterization of recombinant human hypoxia inducible factor $1 \alpha$ in E. coli. World J Microbiol Biotechnol 2011;27(2):453-8.

3. Zaika LL. Spices and herbs: Their antimicrobial activity and its determination. J Food Saf 1998;9:97-118.

4. Singh D, Srivastava RK, Khanduri VP. Marketing strategies and trade of medicinal plants in Uttaranchal: Present and future prospects. Indian Forester 2005;131(3):330-40.

5. Zafar R. Medicinal Plants of India. New Delhi: CBS; 1994. p. 48-61.

6. Zavala MA, Perez S, Perez RM. Antimicrobial screening of some medicinal plants. Phytother Res 1997;11:368-71.

7. Dorman HJ, Deans SG. Antimicrobial agents from plants: Antibacterial activity of plant volatile oils. J Appl Microbiol 2000;88(2):308-16

8. Scazzocchio F, Cometa MF, Tomassini L, Palmery M. Antibacterial activity of Hydrastis canadensis extract and its major isolated alkaloids. Planta Med 2001;67(6):561-3.

9. Lampe WJ. Spicing up a vegetarian diet: Chemoprotective effects of phytochemicals. Am J Clin Nutr 2003;78 3 suppl:579-83.

10. Maiyo ZC, Ngure RM, Matasyoh JC, Chepkorir R. Phytochemical constituents and antimicrobial activities of leaf extracts of the Amaranthus plant species. Afr J Biotechnol 2010;9(21):3178-82.

11. Bauer AW, Kirby WM, Sherris JC, Turck M. Antibiotic susceptibility testing by a standardized single disk method. Am J Clin Pathol $1966 ; 45(4): 493-6$

12. Mendoza MT. Whats new in antimicrobial susceptibility testing. Philipp J Microbiol Infect Dis 1998;27(3):113-5.

13. NCCLS (National Committee for Clinical Laboratory Standard). Performance Standards for Antimicrobial Susceptibility Testing. Vol. 15. Villanova, PA: National Committee for Clinical Laboratory Standard; 1993. p. 100-56

14. Abu-Shanab B, Adwan G, Jarrar N, Abu-Safiya D, Adwan K. Antibacterial activities of some plant extracts utilized in popular medicine in Palestine. Turk J Biol 2004;28:99-102.

15. Harborne JB. Phytochemical Methods Guide to Modern Technique of Plant Analysis. $3^{\text {rd }}$ ed. London: Chapmen all Hall; 1998.

16. Deans SG, Ritchie G. Antibacterial properties of plant essential oils. Int J Food Microbiol 1987;5(2):165-80.

17. Kumar S, Stohlgren TJ, Chong GW. Spatial heterogeneity influences native and nonnative plant species richness. Ecology 2006;87(12):3186-99.

18. Naveed M, Tahir AK, Izhar A, Adil H, Hamid A, Zaheer UD, et al. In vitro antibacterial activity of Cannabis sativa leaf extracts to some selective pathogenicbacterial strains. Int J Biosci 2014;4(4):65-70.

19. Zargari A. Medical Plants. Tehran, Iran: Tehran University Press; 1990.

20. Mirheidar H. Knowledge of Plants. Tehran, Iran: Amir Kabir Press; 1995.

21. Akindele AJ, Adeyemi OO. Anti-inflammatory activity of the aqueous leaf extracts of Byrsocarpus coccineus. Fitoterapia 2007;78(1):25-8.

22. Malairajan P, Geetha G, Narasimhan S, Jessi Kala Veni KV. Analgesic activity of some Indian medicinal plants. J Ethnopharmacol 2006;19(3):425-8

23. Baravalia Y, Kaneria M, Vaghasiya Y, Parekh J, Chanda S. Antioxidant and antibacterial activity of Diospyros ebenum Roxb. Leaf extracts. Turk J Biol 2009;33:159-64

24. Hartung AC, Nair MG, Putnam AR. Isolation and characterization of phytotoxic compounds from asparagus (Asparagus officinalis L.) Roots. J Chem Ecol 1990;16(5):1707-18.

25. Edenharder R, Grunhage D. Free radical scavenging abilities of flavonoids as mechanism of protection against mutagenicity induced by tert-butyl hydroperoxide or cumene hydroperoxide in Salmonella typhimurium TA102 Mutat. Mutat Res 2003;540(1):1-18.

26. Wang M, Tadmor Y, Wu QL, Chin CK, Garrison SA, Simon JE. Quantification of protodioscin and rutin in asparagus shoots by LC/MS and HPLC methods. J Agric Food Chem 2003;51(8):6132-6.

27. Kathad HK, Shah RM, Sheth NR, Patel KN. In vitro antioxidant activity of leaves of Garuga pinnata Roxb. Int J Pharm Res 2010;2(3):9-13.

28. Yadav M, Chatterji S, Gupta SK, Watal G. Preliminary phytochemical screening of six medicinal plants used in traditional medicine. Int $\mathrm{J}$ Pharm Pharm sci 2014;6(5):539-42.

29. Stern DI, Common MS, Barbier EB. Economic growth and environmental degradation: The environmental kuznets curve and sustainable development. World Dev 1996;24(7):1151-60.

30. Rios JL, Recio MC, Máñez S, Giner RM. Natural triterpenoids as antiinflammatory agents. Stud Nat Prod Chem 2000;22:93-143.

31. Prasad RN, Viswanathan S, Devi JR, Nayak V, Swetha VC, Archana BR, et al. Preliminary phytochemical screening and antimicrobial activity of Samanea saman. J Med Plants Res 2008;3(1):45-8.

32. Kale AA, Pawarb AB, Deshpandea NR, Salvekar JP. Antimicrobial activity study of Juglans regia L. J Pharm Res 2011;4(2):331-2.

33. Raj T, Kumar P, Rathee R, Dubey K. Screening of some medicinal plants for their antimicrobial activities. Int $\mathrm{J}$ Pharm Pharm sci 2016;8(5):202-6. Available from: https://www.innovareacademics.in/ journals/index.php/ijpps/article/view/9606/4746. 